\title{
PERMUSYAWARATAN DALAM \\ PERSPEKTIF AL-QURAN \\ (Kajian Tafsir Tematik)
}

\author{
Dudung Abdullah \\ Dosen Fakultas Syariah dan Hukum Universitas Islam Negeri Alauddin Makassar
}

\begin{abstract}
Consultative negotiations are an activity by means of an exchange of opinions on various sides of an issue to be considered and decided then and captured the best for the common good. Koran regard deliberation as noble deeds and important that workshop participants should pay attention to etiquette and manners when deliberation. Deliberation should put their trust in God the AllKnowing and Wise.
\end{abstract}

\section{Keywords:}

Deliberation, Al-Qur'an

\begin{abstract}
Abstrak
Permusyawaratan adalah suatu kegiatan perundingan dengan cara pertukaran pendapat dari berbagai pihak tentang suatu masalah untuk kemudian dipertimbangkan dan diputuskan serta diambil yang terbaik guna kemaslahatan bersama. Al-Quran memandang musyawarah sebagai amalan yang mulia dan penting sehingga peserta musyawarah harus memperhatikan etika dan sikap ketika bermusyawarah. Musyawarah hendaknya bertawakkal kepada Tuhan Yang Maha Mengetahui dan Maha Bijaksana.
\end{abstract}

Kata Kunci:

Musyawarah, Al-Qur'an

\section{A. PENDAHULUAN}

\begin{abstract}
1-Qur'an al-Karim adalah kitab suci umat Islam terdiri dari kumpulan pesan1 pesan Tuhan, diturunkan kepada Nabi Muhammad SAW melalui malaikat 1 Jibril $^{1}$. Ia diturunkan untuk menjadi petunjuk bagi manusia dan alam, "utamanya bagi orang-orang yang mengikuti jalan menuju keridhaan Tuhannya dengan berbagai cara yang ditempuhnya.
\end{abstract}

${ }^{1}$ Abd.Muin Salim, Konsepsi Kekuasaan Politik dalam Al-Qur'an (Jakarta: PT. Raja Grafindo Persada, 1994), h.19

${ }_{2}^{2}$ Muhammad Husain al-Dzahaby, Al-Tafsir wa al-Mufassirūn (Mesir: dar al-Kutub, 1976), h.5, dan lihat Zahir Bin Iwad al-Alma'̄̄, Dirāsat fi al-Tafsir al-Maudū'̄ Li Al-Qur'ān al-Karìm (t.t : t.p., 1985), h.50. 
Dengan rahmat dan kasih sayang, Allah menurunkan al-Qur'an untuk memberikan berbagai kemudahan dalam hidup manusia bukan sebaliknya untuk menimpakan kesulitan hidup, sebagaimana Firman-Nya dalam Q.S.Thaha/20:2

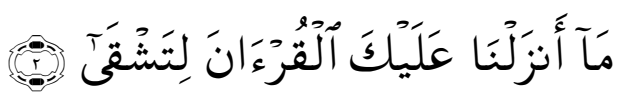

Artinya:

"Kami tidak menurunkan Al Quran ini kepadamu agar kamu menjadi susah"

Di dalam Al-Qur'an termuat berbagai prinsip dan aturan dasar yang dapat dipedomani manusia dalam seluruh aspek kehidupannya. Di dalamnya juga terangkum berbagai tatanan sosial politik yang mengatur tata cara kehidupan bermasyarakat, seperti cara penyeleseian persoalan-persoalan melalui musyawarah.

Term musyawarah (syura) telah lama menjadi wacana publik dan tema-tema pokok pembicaraan di kalangan intelektual (highly educated) baik muslim maupun non muslim yang sangat berpengaruh dalam kehidupan berbangsa dan bernegara.

Manusia sebagai penduduk suatu Negara adalah makhluk sosial "Zoon Politicon" tidak mampu hidup terpisah, terisolasi dari pergaulan masyarakat, karena memerlukan bantuan satu sama lainnya, bantuan yang sangat penting antara lain kebutuhan informasi dan pertukaran pendapat.

Pemberian informasi dan tukar pendapat sudah sejak lama dibicarakan oleh para cendikiawan angkatan Aristoteles yang hidup ratusan tahun sebelum masehi menyangkut sosial, budaya, kemasyarakatan ${ }^{3}$.

Perkembangan masyarakat dan bangsa-bangsa semakin pesat oleh pengaruh globalisasi dan teknologi informasi, hal ini menyebabkan kontak dunia Barat dan Timur, termasuk pengaruh politik Barat terhadap dunia Islam khususnya wacana demokrasi.

Ajaran demokrasi yang sudah lama berkembang di Barat yang dirintis oleh pionir-pionir mereka seperti "John Lock dari Inggris, Thomas Jefferson dari Amerika, Karl Marx dari Jerman, Lenin dari Rusia J.J.Rousseau dan Montesquieu dari Prancis"4. Sampai dewasa ini ajarannya masih berpengaruh terhadap perkembangan demokrasi di berbagai belahan dunia.

Berbeda dengan demokrasi di Barat, di dunia Islam lahir konsepsi dan aplikasi musyawarah. Hal ini dapat dilihat pada masa Nabi sebagai "Rais al-Din dan Rais alBilad di negara Madinah "musyawarah sebagai prinsip kenegaraan dan aturan dalam sistem pemerintahan" ${ }^{5}$ yang begitu intern dipraktekkan Rasulullah SAW., sebagaimana tersirat dalam sebuah riwayat :

${ }^{3}$ Lihat Onong Uchyono Efendi, Ilmu Komunikasi, Teori dan Praktik (Bandung: PT.Remaja Rosda Karya, 1993), h.9

${ }^{4}$ Ismail Badhawiy, Mabda al-Syūrā fi al-syarīat al-Islāmiyah (t.t.: Dar al-Fikri al-Arabiy, 1981), h.6

${ }^{5}$ Harun Nasution, Islam Rasional (Bandung :Mizan, 1996), h.27 
“Dari Abu Hurairah ra dia berkata : "saya tidak pernah melihat seseorang yang paling sering melakukan melakukan musyawarah selain dari Rasulullah SAW"6.

Tradisi musyawarah dipraktekkan pula oleh para sahabat, khususnya para khulafa al Rasyidin pada masa kepemimpinan mereka, yang mengalami perkembangan yang cukup signifikan.

Namun dalam lintasan sejarah perjalanan selanjutnya yakni sejak pergantian sistem pemerintahan dari khilafah ke sistem kerajaan (monarkhi) yang didasarkan atas factor geneologis, semangat dan praktek musyawarah ini mengalami kemandekan. Sistem pemerintahan semacam ini tidak banyak memberi kesempatan untuk mengembangkan konsep syura yang menjadi cerminan suara masyarakat.

Islam melalui bahasa wahyu Al-Qur'an menggunakan istilah Syura/Musyawarah, yang dijadikan sebagai landasan utama dalam kemasyarakatan. Yang luas, secara tegas Al-Qur'an S.Al-Syura/ 42: 38 menyatakan :

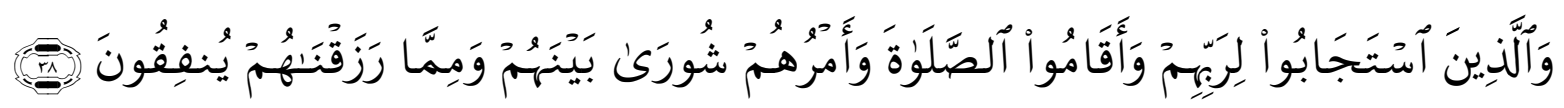

Artinya :

"Dan (bagi) orang-orang yang menerima (mematuhi) seruan Tuhannya dan mendirikan shalat, sedang urusan mereka (diputuskan) dengan musyawarah antara mereka; dan mereka menafkahkan sebagian dari rezki yang Kami berikan kepada mereka."

Kata "Syura"dalam ayat tersebut merupakan kata kunci yang harus ditempuh oleh seseorang dalam berbagai urusan, dan prinsip ini sepenuhnya dilaksanakan oleh Rasulullah SAW dalam kehidupan beliau baik sebagai pribadi maupun sebagai pimpinan dari anggota masyarakat suatu negeri dan prinsip ini juga dipraktekkan oleh para sahabat, khulafau al-Rasyidin dan penguasa muslim seterusnya7.

Sehubungan dengan uraian di atas, tulisan ini mencoba mengeksplorasi musyawarah dalam Al-Qur'an dan berusaha untuk mengelaborasi cakupancakupannya yang berkaitan dengan makna musyawarah. Objek atau lapangan musyawarah serta manfaat yang diperoleh dari musyawarah untuk kehidupan beragama, bermusyawarah dan bernegara.

\section{B. ANALISIS TERMINOLOGIS MUSYAWARAH}

Secara etimologis term musyawarah yang berasal dari bahasa Arab (Al-Quran) " ابد اء شيء واظهاره وعر ضه yaitu (ش و ر ) yang berakar kata sy-w-r شورى "syura" memulai sesuatu, menampakkan dan melebarkannya". Juga mengandung makna mengeluarkan madu dari sarang lebah"

${ }^{6}$ Al-Tirmidziy, Jami al-Shalih-Sunan al-Tirmidzi, IV (t.t.: Mustafā Al-Babī Al-Halabī, 1962 M), h.214 Lihat juga Ismail al-Badhawy, Op.cit., h.11

${ }^{7}$ Lihat Nurcholis madjid, Islam Doktrin dan Peradaban (Jakarta : Paramadina, 1992), h.24

${ }^{8}$ Abi Al-Husain Ahmad bin Faris, Maqōyis al-Lughah, Juz III (t.t. : dar al-Fikr, t.th.), h.226

9 Jamaluddin Muhammad ibn Mukram Ibn al-Manzhur al-Afriqiy al-Mishriy, Lisan al-Arabiy (Beirut : Dar al-Fikri, 1990), h.434 
Dari kata شورى شناور- يشاور- مشاورة dibentuk lafadz fi'il sebahagian ahlu lughah mengatakan bahwa lafadz syāwara-musyawarah berarti mencari pendapat/ buah شikiran seperti mengeluarkan madu dari sarang lebah, dengan wazan (patron) شاور bisa berarti saling mencari/ mengeluarkan pendapat $\left(R a^{\prime} y u n\right)^{10}$.

Kata tersebut selanjutnya mengalami perkembangan arti sehingga mencakup segala sesuatu yang dapat diambil atau dikeluarkan dari yang lain termasuk pendapat. Musyawarah juga dapat berarti mengatakan atau mengajukan sesuatu ${ }^{11}$. Juga berarti perkara yang dimusyawarahkan. ${ }^{12}$

Kata al-syura (اشوري ) dan al-masyurah ( المشور •) mempunyai makna sama13 yang berarti permusyawaratan atau hal bermusyawarah.

Musyawarah dalam konteks terminologis terdapat perbedaan pandangan dalam memberikan defenisi. Abdul Hamid Al-Anshari mengatakan bahwa syura (musyawarah) berarti saling merundingkan atau bertukar pendapat mengenai suatu masalah atau meminta pendapat dari berbagai pihak untuk kemudian dipertimbangkan dan diambil yang terbaik demi kemaslahatan bersama ${ }^{14}$.

Louis Ma'Lou menyatakan syura adalah majelis yang dibentuk untuk memperdengarkan saran dan ide sebagaimana mestinya dan terorganisir dalam aturan $^{15}$. Dalam Ensiklopedia Hukum Islam dikatakan bahwa musyawarah adalah pembahasan bersama dengan maksud mencapai penyeleseian masalah bersama ${ }^{16}$.

Dari paparan beberapa definisi di atas penulis mentransfer dalam bahasa rangkuman bahwa musyawarah adalah suatu perundingan tentang suatu urusan yang baik untuk mendapatkan buah pikiran dengan maksud mencari yang terbaik guna memperoleh yang terbaik guna memperoleh kemaslahatan bersama. Dengan demikian suatu majelis Syura atau dengan bahasa yang populis Majelis Permusyawaratan Rakyat sebagai lembaga legislatif.

\section{TERM MUSYAWARAH DALAM AYAT AL-QUR'AN}

Dalam Al-Qur'an terdapat tiga ayat yang membicarakan musyawarah yakni. Q.S.Al-Syura/ 42:38 dengan menggunakan term syura (شورى), Q.S. Al-Baqarah/2:233 dengan menggunakan term tasyawur (تشاور) dan Q.S. Ali Imran/3: 159 menggunakan term syawir (شاور) (شاور) Ayat 38 surah Al-syura adalah yang pertama kali diturunkan

\footnotetext{
${ }^{10}$ Ibrahim Anis, et.al, Mu jam al-Wasīth, Juz I (Teheran : Maktabah al-Ilmiyah, t.th), h.501

11 M.Quraish Shihab, Wawasan Al-Quran (Bandung : Mizan , 2001), h.469. Term musyawarah pada dasarnya hanya digunakan pada hal-hal yang baik dan bermanfaat, seperti halnya madu tidak saja manis , tetapi juga obat untuk berbagai penyakit dan sekaligus sumber kesehatan dan kekuatan.

${ }^{12}$ Lihat al-Raghib al-Ashfahaniy, Mufradāt alfāzh Al-Qurān (Beirut: Dār al-Syāmiyah, 1992), h.469

${ }^{13}$ Lihat Jamaluddin Ibn Mukram Ibn al-Manzhur al-Afriqiy al-Mishriy, Lisan al-Arabī, VI (Beirut : Dar al-Fikr, 1990), h.105-106

${ }^{14}$ Abd. Al-Hamid Ismail al-Anshoriy, Nizhām al-Hukmi fī al Islām (Qothar : Dār al- Qathrayin alFujaah, 1985), h.45

${ }^{15}$ Lihat Louis Ma'louf, al-Munjid fi al-Lughah wa al- 'Alam (Beirut : Dar Al-Masyriq, 1986), h.408

${ }^{16}$ Abdul Azis et.al (Ed.), Ensiklopedia Hukum Islam (Jakarta : PT Ikhtiar Baru Van Hoeve, 1986), h.1264

${ }^{17}$ Muhammad Fuad Abd. Al-Baqiy, al-Mu'jam al-Mufahras Li alfāzh al-Qur'ān al-Karīm (Beirut : Dār al-Fikr, 1987), h.391
} 
dan termasuk kelompok ayat/surah Makkiyah sedang dua ayat lain termasuk kelompok ayat/surat Madaniyah atau setelah Rasulullah hijrah ke Madinah.

1. Ayat Pertama Q.S.Al-Syura/ $42: 38$

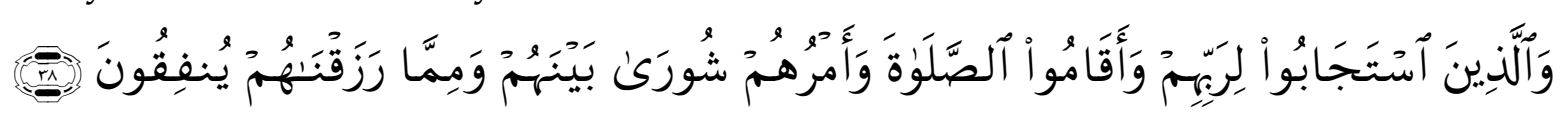

Artinya :

"Dan (bagi) orang-orang yang menerima (mematuhi) seruan Tuhannya dan mendirikan shalat, sedang urusan mereka (diputuskan) dengan musyawarat antara mereka; dan mereka menafkahkan sebagian dari rezki yang Kami berikan kepada mereka".

Ayat ini diturunkan sebagai pujian kepada kelompok muslim Madinah (kaum Anshor) yang bersedia membela nabi SAW dan menyepakati hal tersebut melalui musyawarah yang mereka laksanakan di rumah Abu Ayyub Al-Anshari ${ }^{18}$. Namun demikian ayat ini juga berlaku umum mencakup setiap kelompok yang melakukan musyawarah.

2. Ayat Kedua Q.S. Al-Baqarah/ 2: 233

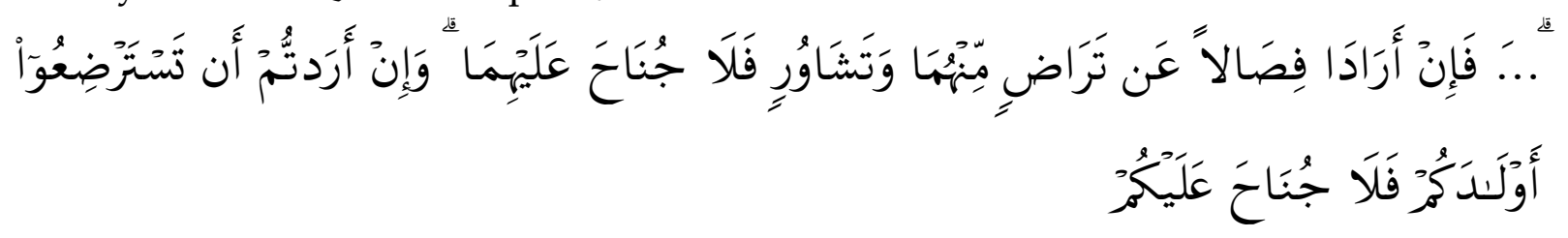

"Apabila keduanya ingin menyapih (sebelum dua tahun) dengan kerelaan keduanya dan permusyawaratan, Maka tidak ada dosa atas keduanya."

Ayat ini membicarakan bagaiman seharusnya hubungan suami-istri saat mengambil keputusan yang berkaitan dengan masalah rumah tangga dan hal yang berkaitan dengan anak-anak seperti menyapih pengurusan anak ${ }^{19}$. Al-Qur'an memberi petunjuk agar persoalan itu dan juga persoalan-persoalan lainnya dimusyawarahkan dengan baik antara suami-istri.

3. Ayat ketiga Q.S.Ali imran/ 3:159

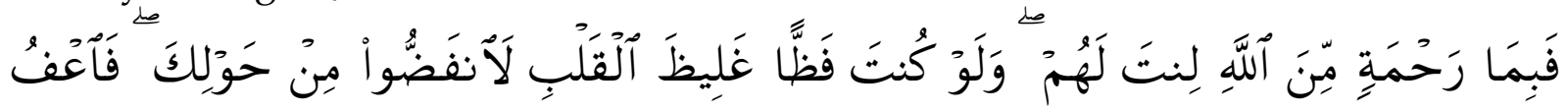

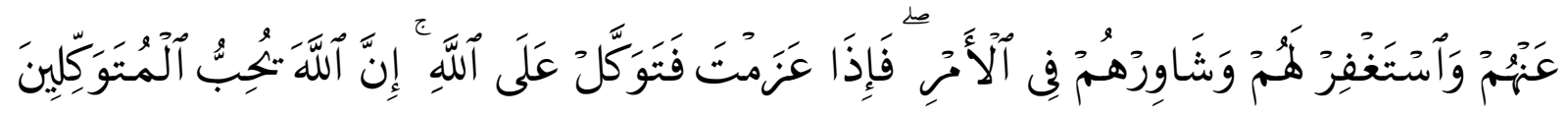

Artinya :

"Maka disebabkan rahmat dari Allah-lah kamu Berlaku lemah lembut terhadap mereka. Sekiranya kamu bersikap keras lagi berhati kasar, tentulah mereka menjauhkan diri dari

\footnotetext{
${ }^{18}$ M.Quraish Shihab, Wawasan -Loc. Cit

${ }^{19}$ Ibn . Katsir, Ismail, Tafsir al-Qur'an al-Azhìm (Singapura : Sulaiman Mar'iy, t.th.), h.284
} 
sekelilingmu. karena itu ma'afkanlah mereka, mohonkanlah ampun bagi mereka, dan bermusyawaratlah dengan mereka dalam urusan itu. kemudian apabila kamu telah membulatkan tekad, Maka bertawakkallah kepada Allah. Sesungguhnya Allah menyukai orang-orang yang bertawakkal kepada-Nya."

Secara lafzhiyah (redaksional), ayat ini ditujukan kepada Rasulullah SAW agar memusyawarahkan persoalan-persoalan tertentu dengan para sahabat atau anggota masyarakatnya. Tetapi ayat ini juga memaparkan kepada setiap mukmin, khususnya kepada setiap pemimpin agar bermusyawarah dengan anggotanya ${ }^{20}$.

Ayat ini turun setelah terjadinya peperangan Uhud (ghazwati Uhud) yang kurang menguntungkan bagi kaum muslimin karena dipecundangi oleh kaum kafir quraisy. Namun nabi tetap sabar dalam menghadapi musibah tersebut, bersikap lemah lembut dan tidak mencibir kesalahan sahabat-sahabatnya dan nabi tetap bermusyawarah baik dalam keadaan gawat maupun dalam keadaan damai (fi al harb wa al silmi ${ }^{21}$.

Sebenarnya cukup banyak hal dalam peristiwa perang Uhud yang dapat mengundang emosi manusia untuk marah, namun demikian cukup banyak pula bukti yang menunjukkan kelemahlembutan Nabi Saw, yang membuka jalan kenyamanan untuk bermusyawarah.

\section{PERAN DAN LAPANGAN MUSYAWARAH}

Dengan melihat beberapa pernyataan Al-Qur'an dan Hadis tentang musyawarah yang bisa dijadikan landasan hukum, menunjukkan musyawarah memiliki peranan yang penting dan strategis di dalam kehidupan sosial kemasyarakatan dan kenegaraan. Maka wajarlah jika Rasulullah SAW begitu sering bermusyawarah dan kerja bareng bersama sahabat dalam kesehariannya, sebagaimana kandungan hadis dari Abu Hurairah:

"Dia berkata: "Saya tidak pernah melihat seseorang yang paling sering melakukan musyawarah selain dari Rasulullah SAW." 22

Kendati pun musyawarah mempunyai peran yang sangat urgen dalam ajaran Islam, namun hal itu tidak berarti segala sesuatu menjadi obyek atau lapangan musyawarah. Tiga ayat Al-Qur'an yang telah diutarakan di atas bisa memberikan gambaran bagaimana tuntutan untuk bermusyawarah dan lapangan yang merupakan wilayah untuk dimusyawarahkan.

Lapangan atau obyek musyawarah bisa dilihat dari teks/lafaz fi al-amri ( فى الامر) dalam Q.S.Ali Imran/3: 159 yang diterjemahkan dengan "dalam urusan itu". Dari segi konteks ayat bahwa lapangan musyawarah dalam ayat tersebut berkaitan

${ }^{20}$ Al-Sayyid Muhammad rasyid Ridha , Tafsir al-Qur'ān al-Hakīm al-Manār, IV,( Beirut : Dar al-Maarif, t.th.), h. 198

${ }^{21}$ Ibid dan lihat Ahmad Mustafa al-Maraghy, Tafsir al-Maragī, IV (Kairo : Mustafa al-Babī al-Halabī

${ }^{22}$ Al-Tirmidzī, Loc.Cit 
dengan persoalan peperangan ${ }^{23}$. Oleh karena itu ada pendapat di kalangan ulama yang membatasi bahwa lapangan musyawarah menurut ayat tersebut hanya yang berkaitan dengan persolan peperangan. Namun pandangan ini tidak didukung oleh praktek Nabi SAW.

Rasyid Ridha mengomentari lafaz fi al-amri (فى الامر) bahwa lapangan musyawarah di sini tidak terbatas pada peperangan, akan tetapi bisa urusan yang lebih luas, seperti urusan politik kenegaraan dan kemasyarakatan, pada masa perang dan damai, pada masa kacau dan masa aman, urusan tersebut tetap dibatasi pada wilayah keduniaan, bukan persoalan ibadah makhdhah ${ }^{24}$.

Kata fi al-amri ( فى الامر) masih pula ditambah dengan lafaz wa amruhum ( و امرهم) dalam surah Al-Syura/42 : 38 adalah urusan umat khususnya kaum muslimin dalam kategori yang ma'ruf ( الامر المعروف) yang dibenarkan oleh pemerintahan yang baku dan berlaku dalam adat kebiasaan serta sesuai dengan situasi dan kondisi suatu daerah atau Negara. Persoalan agama yang sudah jelas dan ditetapkan oleh wahyu tidak lagi menjadi lapangan musyawarah, sebab andaikata persoalan agama seperti aqidah, ibadah ( $\left.t a^{\prime} a b b u d i\right)$ ditetapkan oleh hasil musyawarah maka agama ini aturan manusia ( وضع البشر) bukan aturan Tuhan ( وضع الهى ) .

$A l-A m r$ atau urusan yang bukan wilayah lapangan musyawarah adalah urusan yang hanya wewenang Allah semata-mata, hal ini ditemukan dalam Al-Qur'an, seperti terlihat dalam jawaban Allah tentang ruh (Q.S.Al-Isra/ 17:85), tentang datangnya kiamat Q.S.An-Nāziat/ 79:42. Demikian juga soal taubat (baca misalnya Q.S.A1i Imrān/3: 128 dan persoalan-persoalan gaib lainnya. Dalam konteks seperti ini tidak ada lagi campur tangan manusia dan hanya mempunyai pilihan untuk menerima ketetapan-ketetapan tersebut sebagai bukti dan ekspresi dan keimanan dan ketakwaan kepada Allah dan Rasul-Nya. Untuk itu Al-Qur'an S.al-Ahzab/33:36 secara tegas menyatakan:

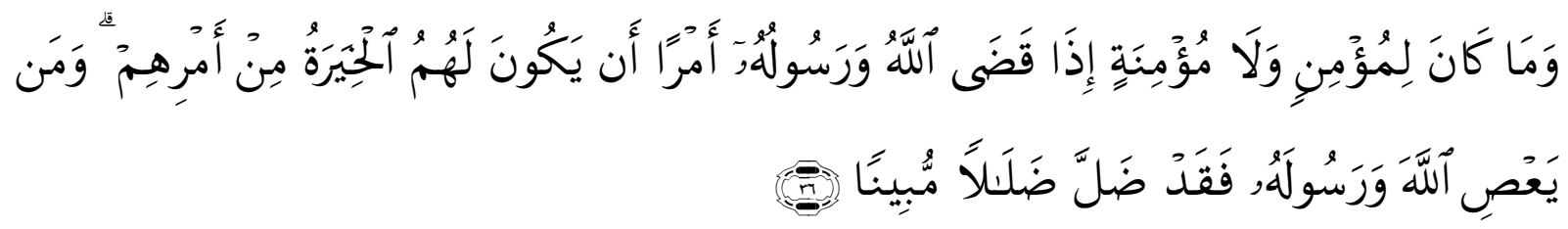

Artinya:

"Dia tidaklah patut bagi laki-laki yang mu'min dan tidak (pula) bagi perempuan yang mu'min, apabila Allah dan Rasul-Nya telah menetapkan suatu ketetapan, akan ada bagi mereka pilihan (yang lain) tentang urusan mereka. Dan barangsiapa yang mendurhakai Allah dan Rasul-Nya maka sungguhlah dia telah sesat, sesat yang nyata."

${ }^{23}$ M.Quraish Shihab, Tafsir al-Mishbah: Pesan, Kesan, dan Keserasian Al-Quran, vol.2 (Jakarta: Lentera Hati, 2004), h.245

24 Al-Sayyid Muhammad Rasyid Ridha, Op.Cit., h.199, dan Lihat Subhi Abd.Said, Al-Sulthatu wa alHurriyatu fi al-Nizham al-Islamī (t.t. : Dar al-Fikri al-Arabī,t.th), h.135

25 Al-Sayyid Muhammad Rasyid Ridha , Loc.Cit., h.199, dan Lihat Sayyid Quthub, Fi Zhilal al-Qur'an (t.t. : Dar al-Syuruq, 1992), h.3165 
Urusan (al-amr) yang merupakan lapangan musyawarah mulai dari lingkungan keluarga. Sebagai bentuk miniatur masyarakat. Sampai skala besar pemerintahan suatu negara bahkan dunia Internasional. Contoh kasus keluarga seperti kandungan Q.S.Al-Baqarah/2:233 tentang penyapihan penyusuan anak (fishal) yang menyoroti "hak si bayi untuk mendapatkan biaya. Di sini ada landasan hukum yang perlu ditegakkan yakni adanya kerelaan dan tidak ada pihak yang dirugikan" ${ }^{26}$. Intinya semua persoalan yang dihadapi anggota keluarga harus dibicarakan dan dicarikan solusinya dengan keputusan yang terbaik. Memang musyawarah seharusnya menjadi landasan pokok dalam membina kehidupan berkeluarga.

Lapangan musyawarah yang dilansir para ulama adalah persoalan yang tidak terdapat nashnya_ dalam Al-Quran dan hadis Rasulullah SAW, atau ada nash mengatur, hanya saja bersifat Ghairul Qathi al-Dalalaah (dalalahnya tidak tegas) ${ }^{27}$. Atau pada masalah yang berhubungan dengan kemasyarakatan ${ }^{28}$. Sedangkan persoalan-persoalan yang ada petunjuknya secara tegas dan jelas baik melalui AlQuran maupun sunnah Rasulullah SAW tidak menjadi lapangan musyawarah.

Asumsi tersebut bisa dipahami dari cara musyawarah yang dipraktekkan Nabi SAW bersama para sahabatnya. Mereka menyadari benar, mereka tidak mengajukan saran menyangkut hal-hal yang mereka telah ketahui adanya petunjuk ilahi. Ketika Nabi SAW memilih satu lokasi untuk pasukan kaum muslimin dalam perang badar, sahabat beliau, Al-Khubbab Ibn al-Mundzir mengajukan pertanyaan kepada Nabi : "Apakah ini tempat yang diperintahkan Allah kepadamu, atau tempat ini adalah pilihanmu berdasarkan strategi perang dan siasat tipu muslihat ? ketika Nabi menjawab bahwa pilihan itu adalah pilihan berdasar pada pertimbangan beliau, barulah al- Khubbab menyarankan lokasi lain, yang ternyata disetujui oleh Nabi SAW.

Islam memberi posisi dan porsi istimewa musyawarah, sejak lingkungan keluarga sampai kehidupan dalam skala besar kemasyarakatan dan kenegaraan, namun dimaklumi sangat terbatas ayatnya dalam al-Quran itupun dalam bentuk yang sangat umum tanpa menjelaskan secara rinci tentang cara-cara bermusyawarah.

\section{E. ETIKA MUSYAWARAH}

Kegiatan musyawarah merupakan hal yang sangat penting yang harus dilakukan oleh umat Islam dalam persoalan yang muncul dalam kehidupan. Musyawarah menuntut manusia untuk bisa merubah taraf kehidupan ke tingkat yang lebih baik. Oleh karenanya untuk mencapai maksud tersebut, ada beberapa hal

${ }^{26}$ Ibid, h.414 dan Lihat Idris Thaha, Demokrasi Religius: Pemikiran Politik Nurcholis Madjid dan M.Amien Rais (Bandung : Mizan media Utama,2005), h.35

${ }^{27}$ Lihat Taqiuddin Ibn Taimiyah , Al-Siyāsah al-Sar'Iyyah (Beirut: Dar al-Kutub al-Ilmiah, 1988, h.135, dan Lihat Abd.Hamid Ismail , Al-Syūra Waatsaruhā fi al-Dimaqrāthiyah (Kiaro :Maktabah al-Salafiyah, 1981), h. 8

${ }^{28}$ M.Quraish Shihab ,Op.Cit.- al-Misbah, h.246 
yang penting diperhatikan, yang secara beruntun diperintahkan kepada Nabi SAW sebagaimana terkandung dalam ayat-ayat tentang musyawarah, M.Quraish Shihab melansir ada tiga sifat dan sikap yang harus dilakukan sebelum musyawarah ${ }^{29}$ :

1. Pertama, Sikap Lemah Lembut

Seseorang yang melakukan musyawarah apalagi sebagai pemimpin harus mengindari tutur kata yang kasar serta keras kepala, karena jika sifat itu dilakukan maka mitra musyawarah akan meninggalkan majelis. Petunjuk ini dikandung oleh frase Al-Imran/3:159 لَكَمْ لِنت

2. Kedua, memberi maaf dan membuka lembaran baru

Sikap ini dapat dipahami dari potongan ayat فا عف عنهم (maafkan mereka ). Maaf secara harfiah berarti menghapus bekas luka di hati akibat perlakuan pihak lain yang dinilai tidak wajar. Ini perlu karena kejernihan hati dan kecerahan pikiran sangat diperlukan ketika bermusyawarah. Di sisi lain peserta musyawarah mempersiapkan mental yang selalu siap memberi maaf. Karena mungkin saja ketika bermusyawarah terjadi perbedaan pendapat, atau bahkan keluar perkataan yang menyinggung perasaan pihak lain.

3. Ketiga, hubungan baik dengan Tuhan

Seseorang yang melakukan musyawarah hendaklah menyadari bahwa kemampuan akal dan ketajaman analisis belum cukup untuk mendapatkan hasil yang optimal, sebab masih ada sesuatu yang dijangkau oleh kemampuan akal. Jika demikian untuk mencapai hasil yang terbaik ketika musyawarah, hubungan peserta musyawarah dengan Tuhan harus harmonis, antara lain permohonan ampunan ilahi, meminta petunjuk dan bertawakkal kepada-Nya.

\section{F. MANFAAT MUSYAWARAH}

Secara jelas dapat terbaca tentang pentingnya bermusyawarah baik itu dalam Al-Quran, Al-Sunnah maupun praktik dalam perjalanan kehidupan manusia. Praktik musyawarah sudah sangat lama eksis mulai dari lingkungan keluarga sampai meluas ke Wilayah Negara dan dunia Internasional, dengan bentuk dan cara yang berbeda, sesuai dengan perkembangan zaman. Itulah salah satu hikmah tidak adanya penuturan secara rinci tentang musyawarah, agar bisa berlaku secara fleksibel untuk berbagai tempat dan masa.

Posisi musyawarah yang sangat penting dan strategis, utamanya ketika "Ulu alamri" dengan ketetapannya (ijma') yang menjadi kebijaksanaan, ${ }^{30}$ dan terus meningkat menjadi hukum dan perundang-undangan akan sangat menentukan perjalanan suatu daerah atau Negara.

\footnotetext{
${ }^{29}$ M.Quraish Shihab, Wawasan, Op.Cit., h.473-474

${ }^{30}$ Ulu al-Amri adalah gabungan al-Umara dan Ulama Lihat Taqiuddin Ibnu Taimiyah, Op.Cit., h.136
} 
Jika dikaji lebih mendalam akan banyak manfaat yang dapat dipetik dari pelaksanaan musyawarah, antara lain :

1. Musyawarah menjadi sarana untuk mengungkap kemampuan dan kesiapan, sehingga umat dapat mengambil manfaat dari kemampuan itu.

2. Musyawarah melatih ikut andil dalam pemerintahan memperkaya pengalaman, mengasah penalaran akal dan kecerdasan.

3. Musyawarah menguatkan tekad, mendatangkan keberhasilan, menjelaskan kebenaran, memperluas alasan, menhindarkan diri dari penyesalan, mengambil kesimpulan yang benar sehingga timbul kepastian bertindak yang sesuai dengan prinsip-prinsip yang telah ditetapkan.

4. Menjaga agar tidak terjadi kekeliruan dan meminimalisir atau memperkecil kemungkinan menemui kegagalan, karena kegagalan setelah bermusyawarah dapat dimaklumi dan menghindarkan celaan.

5. Musyawarah dapat mengungkap tabiat dan kualitas seseorang yang terlibat dimintai pendapat dan pertimbangan mengenai suatu persoalan.

6. Musyawarah dapat melapangkan dada untuk menerima kesalahan dan memberi maaf atau menciptakan stabilitas emosi. ${ }^{31}$

Dengan melihat banyak manfaat, maka musyawarah merupakan suatu keharusan bagi setiap umat manusia, terutama bagi setiap umat manusia, terutama bagi para pemimpin, agar persoalan-persoalan umat ditanggulangi melalui musyawarah.

Musyawarah yang dilaksanakan di lingkup rumah tangga untuk mencapai keluarga bahagia, Sakinah, Mawaddah, dan Rahmah. Musyawarah yang diselenggarakan di lingkup masyarakat dengan harapan terciptanya masyarakat yang ideal dan harmonis, dan musyawarah yang dilaksanakan yang lebih umum dan luas yakni dalam wilayah Negara beserta Lembaga-Lembaganya untuk mewujudkan kemaslahatan umat di wilayahnya.

\section{G. KESIMPULAN}

Dari uraian di atas dapat ditarik beberapa kesimpulan penting, antara lain, musyawarah adalah suatu kegiatan perundingan dengan cara bertukar pendapat dari berbagai pihak mengenai suatu masalah untuk kemudian dipertimbangkan dan diputuskan serta diambil yang terbaik demi kemaslahatan bersama.

Musyawarah dalam Islam merupakan suatu amalan yang mulia dan penting sehingga peserta musyawarah senantiasa memperhatikan etika dan sikap bermusyawarah sambil bertawakkal kepada Tuhan Yang Maha Mengetahui dan Maha Bijaksana.

Lapangan atau objek Musyawarah adalah segala problema kehidupan manusia. Namun demikian, tidak semua persoalan dalam Islam bisa seleseikan dengan cara

\footnotetext{
${ }^{31}$ Lihat Idris Thaha, Op.Cit., h.37
} 
bermusyawarah. Musyawarah hanya dilaksanakan dalam masalah yang tidak disebutkan secara tegas pada nash Al-Quran dan Sunnah Rasul.

Banyak manfaat yang bisa dipetik dari musyawarah, namun yang paling penting adalah menghormati dan mentaati keputusan yang diambil atas dasar musyawarah, dengan harapan bisa meraih kesuksesan dan kemaslahatan bersama mulai dari lingkungan keluarga, masyarakat sampai kehidupan bangsa dan Negara.

\section{Daftar Pustaka}

Alquran al Karim

Al-Baqī al-Mishrī, Muhammad Fuad. Al-mu'jam Li alfā̄h Al-Qur'ā̄ al-Karìm. Beirut : Dar al-Fikr, 1987

Al-Afriqī al-Mishrī, Jamaluddin Muhammad Ibn Mukram ibn al-Manzhūr. Lisan alArabi. Beirut : Dar al-Fikr, 1990

Abd. Said, Subhi, Al-Sulthatu wa al-Hurriyah fi Nizham al-Islami-t.th

Anis, Ibrahim, et.al. Mu'jam Li al-Wasith, Juz I. Teheran :Maktabah al-Ilmiyā, 1992

Al-Afriqī al-Mishrī, Jamaluddin Muhammad Ibn Mukram ibn al-Manzhūr. Lisan alArabi. Beirut : Dar al-Fikr, 1990

Al-Alma'ī, Zahir Ibn Mukram Bin Iwad. Diras̄ah fi al-Tafsìr al-Maudu’īLi al-Qur'ā̄ alKarim. t.t : t.p, 1985

Al-Anshori, Abd al-Hamid Ismail. Nizham al-Hukmi Fi al-Islam. Qathar : Dar alQathariyin al-Fujaah, 1985

Al-Ashfahani, Al-Raghib. Mufradał Alfāzh al-Qur'ā̄. Beirut : Dar al-Syamiyah,1992

Al-Dzahabī, Muhammad Husain. Al-Tafsir wa al-Mufassirun. Mesir : Dār al-Kutub, 1976

Al-Maragī, Ahmad Mustafa. Tafsir al-Marāgì, IV. Kairo : Mustafa al-Babīal-Halabī wa Auladun, 1962

Al-Tirmidzī, Jami' al-Shalih al- Tirmidzī, IV, t.t : Mustafa al-Babī al-Halabī, 1962

Azis, Abdul, et.al, Ensiklopedi Hukum Islam. Jakarta : PT.Ichtiar Baru Van Hoeve, 1996

Badawī, Ismail. Mabda al-Syū̄a- fi al-Syariàt al-Islamiyah, t.t : Dar al-Fikri al-Arabbī, 1981

Efendy, Onong Uchyono, Ilmu Komunikasi, Teori dan Praktek. Bandung : PT.Remaja Rosda Karya, 1993

Ibn Katsir, Ismail. Tafsir al-Quran Al-Azhim, Singapura : Sulaiman Mar'I, t.th.

Ibn Taimiyah, Taqiuddin, Al-Siyasah Al-Syar'iyyah, Beirut : dar al-Kutub al-Islamiyah, 1988

Ismail, Abd.Hamid, Al-Syura wa al atsaruhā Fi al-Dimoqrathiyah, Kairo : Maktabah alSalafiyah, 1981

Nasution, Harun, Islam Rasional, Bandung : Mizan, 1996 
Madjid, Nurcholis, Islam Doktrin dan Peradaban, Jakarta: Paramadina, 1992

Ma'louf, Louis, al-Munjid fi al-Lughah Wa al-'Alam, Beirut : Dar al-Masyriq, 1986

Quthub, Sayyid, Fi Zhilal al-Qur'ā̄, V, t.t.: dar al-Syurūq, 1992

Ridha, al-Sayyid Muhammad Rasyid, Tafsir Al-Qur'añ Al-Hakīm al-Manār, IV. Beirut : Dar al-Maa'rif, t.th

Salim , Abd.Muin, Konsepsi Kekuasaan Politik Dalam Al-Qur'an. Jakarta : PT.Raja Grafindo Persada, 1994

Shihab, M.Quraish . Wawasan al-Qur'an, Bandung : Mizan, 2001 Tafsir Al-Mishbah, Vol.2, Jakarta : Lentera Hati, 2004

Thaha, Idris, Demokrasi Religius : Pemikiran Praktik Nurcholis Madjid dan M.Amien Rais. Bandung : Mizan Media Utama, 2005

Zakariya, Abi al-Husain Ahmad bin Faris, Maqoyis al-Lughah, Juz III, t.t : Dar al-Fikr, t.th. 